\title{
Keperluan Peta Kerentanan Bencana sebagai Input dalam Pengurusan Guna Tanah: Kajian Kes Universiti Kebangsaan Malaysia
}

(The Needs of Disaster Susceptibility Map as an Input in Land Use Management: A Case Study of Universiti Kebangsaan Malaysia)

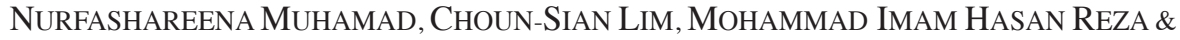 \\ JOY JACQUELINE PEREIRA*
}

\begin{abstract}
ABSTRAK
Limpahan pesat aktiviti tepu bina di UKM Bangi untuk memenuhi kehendak dan juga keperluan warganya menjadikan ia setara fungsi satu pekan kecil. Di samping pembangunan yang pesat, UKM turut mengalami insiden kegagalan cerun, tanah runtuh dan banjir kecil di beberapa kawasan dalam kampus. Kajian ini direka untuk menyepadukan maklumat pelbagai dimensi untuk menyokong membuat keputusan dalam pengurusan guna tanah untuk menangani isu bencana di kampus ini. Objektif kajian adalah untuk: mengenal pasti maklumat pelbagai dimensi yang menyumbang kepada bencana di UKM dan membangunkan satu peta kerentanan tanah runtuh dan banjir untuk menyokong dalam membuat keputusan secara termaklum. Melalui pendekatan heuristik, tiga kaedah utama telah digunakan untuk menghasilkan peta kerentanan tanah runtuh dan banjir iaitu: analisis kandungan untuk mengenal pasti kriteria yang menyumbang kepada tanah runtuh dan banjir; elisitasi pakar untuk memberi nilai pemberat terhadap kriteria; dan analisis tindan-lapis untuk memproses dan menjana peta tematik. Kriteria yang menyumbang kepada tanah runtuh dan banjir dikategorikan kepada faktor hujan, topografi, struktur geologi dan ciri-ciri geomorfologi yang seterusnya diberi nilai pemberat. Peta kerentanan tanah runtuh yang terhasil menunjukkan kelas kerentanan tinggi merupakan kelas terbesar di UKM dengan keluasan sebanyak $6.10 \mathrm{~km}^{2}$ bersamaan $51.91 \%$ daripada jumlah keluasan asal kampus. Analisis terhadap lokasi insiden lepas mendapati kesemua taburan tanah runtuh berlaku pada kelas kerentanan sederhana, tinggi dan sangat tinggi. Hampir separuh daripada jumlah taburan tanah runtuh berlaku pada kelas kerentanan tinggi iaitu 57.14\% yang merupakan peratusan terbesar. Peta kerentanan banjir menunjukkan UKM turut terdedah kepada banjir. Majoriti kawasan kampus didominasi oleh kelas kerentanan sederhana dengan keluasan sebanyak $6.5 \mathrm{~km}^{2}$ kira-kira hampir $56 \%$ daripada keluasan asal. Aset penting universiti dan laluan utama kampus ini yang bersebelahan dengan saliran sungai terletak di dalam kawasan berkerentanan tinggi. Situasi ini agak membimbangkan kerana terdapat infrastruktur penting di sekitar kawasan ini. Input berguna yang diperoleh melalui kajian ini telah menunjukkan keupayaan peta kerentanan tanah runtuh dan banjir sebagai medium yang bermaklumat dalam perancangan guna tanah sebelum menjalankan sebarang aktiviti pembangunan di sesuatu kawasan.
\end{abstract}

Kata kunci: GIS; pengurangan risiko bencana; perancangan guna tanah; peta kerentanan bahaya; UKM

ABSTRACT

The rapid overflow of built-up activities in UKM to meet the needs of the campus deems it a small town. In conjunction with this rapid development, UKM has experienced slope failures, landslides and small inundation in several areas within the campus. This study is designed to integrate multi-dimensional information to support decision-making in land use management to address disaster issues in this campus. The objectives were to: identify the various dimensions of information that contributed to disasters in UKM; and develop a landslide and flood susceptibility map to support informed decision-making. The study employed a heuristic approach and three main methods including: content analysis to identify criteria that contribute to landslides and floods; expert elicitation to provide weightage; and overlay analysis to produce thematic maps. Criteria that contribute to landslides and floods are categorized into precipitation, topography, geological structure and geomorphological characteristics that are weighted according to expert input. Landslide susceptibility map shows high susceptibility class is the largest at $6.10 \mathrm{~km} 2$ equivalent to $51.91 \%$ of the total area of campus. Analysis of past incidences found that all landslides occurred in medium, high and very high susceptibility classes. About half of the total landslides amounting to $57.14 \%$ are located in high susceptibility classes and this represents the largest percentage. Flood susceptibility map indicates that UKM is also exposed to flooding. The moderate susceptibility class dominates the campus at $6.5 \mathrm{~km} 2$, which is about $56 \%$ of the total area. The university's asset and the main route of this campus, which is adjacent to a river is located within the high susceptibility area. The situation is quite alarming as important infrastructure is located within this area. The findings reflect the capability of landslide and flood susceptibility maps as an informative medium in land use planning before executing any development activities in a particular area.

Keywords: GIS; disaster risk reduction; land use planning; hazard susceptibility map; UKM 


\section{Pengenalan}

Limpahan pesat aktiviti tepu bina di dalam kampus induk Universiti Kebangsaan Malaysia (UKM), Bangi bersama keluasan kawasan, jumlah populasi dan juga kepelbagaian aktiviti kompleks telah membentuk institusi ini sebagai satu pekan kecil. Namun, kampus ini dilihat dibina pada kawasan yang tidak bersesuaian (Mokhtar \& Mohd Afif 2013; Nurfashareena et al. 2013). Justeru, kampus ini kerap kali mengalami insiden kegagalan cerun, tanah runtuh dan kenaikan air di beberapa kawasan dalam kampus (Ibrahim 1987, 1984; Mokhtar \& Mohd Afif 2013; Mokhtar et al. 2011; Nurfashareena 2016; Nurfashareena et al. 2013). Beberapa insiden yang berlaku ini turut mengalami perulangan kejadian pada beberapa lokasi yang telah dikenal pasti.

Menurut Ibrahim $(1987,1984)$, sejak UKM mula beroperasi, antara tahun 1977 sehingga 1984 terdapat 19 lokasi cerun di UKM telah dilaporkan mengalami tanah runtuh. Sementara dalam Ibrahim (1987) lagi, 75 lokasi cerun buatan di kampus UKM telah pun dikenal pasti sebagai cerun yang gagal secara geomorfologinya akibat proses gelinciran dan gelongsoran tanah. Walau bagaimanapun, koordinat lokasi lampau ini gagal dikesan. Mokhtar et al. (2011) turut melaporkan terdapat empat daripada 12 lokasi cerun bermasalah (cerun yang pernah mengalami tanah runtuh) di sekitar kampus UKM yang dikategorikan tahap kebolehruntuhannya sebagai kritikal. Pendokumentasian lokasi lampau ini adalah penting sebagai rujukan penilaian kebolehruntuhan cerun pada masa hadapan.

Untuk kajian ini, lokasi tanah runtuh yang berjaya dikumpul untuk tujuan pengarkiban hanya daripada tahun 2009 hingga 2014 kerana insiden yang berlaku sebelum tahun 2009 hanya dapat dijejak melalui sumber tertiar. UKM belum pernah mengalami insiden banjir besar yang memberi impak kepada infrastruktur dan warga kampus. Berdasarkan perbincangan dengan beberapa pegawai dan jurutera senior yang bertugas di Jabatan Penyelenggaraan dan Pembangunan (JPP-UKM) yang kini dikenali sebagai Prasarana UKM, kampus ini hanya berhadapan dengan situasi kenaikan air di sesetengah kawasan apabila berlakunya hujan lebat yang berlarutan. Prasarana UKM bertanggungjawab terhadap penyelenggaraan kampus ini termasuklah segala koordinasi berkaitan bencana di UKM yang lazimnya memerlukan sumber rujukan berasaskan bukti yang berupaya menyokong proses membuat keputusan secara berkesan.

Pemetaan kerentanan bencana merupakan satu medium penting yang dapat menyumbang maklumat berdasarkan keadaan persekitaran tempatan yang cenderung mengalami bencana di samping dapat memberi indikasi am bencana pada masa hadapan (Magliulo et al. 2009; McDonald et al. 2004; Nuriah et al. 2013). Kerentanan dijelaskan sebagai kecenderungan sesuatu kawasan untuk berlakunya bencana (Santangelo et al. 2011). Berdasarkan kekerapan UKM mengalami tanah runtuh dan kewujudan insiden kenaikan paras air di beberapa lokasi, kajian ini menilai tahap kerentanan dan kecenderungan kawasan kajian untuk mengalami bencana melalui peta kerentanan tanah runtuh dan banjir.

Pemetaan ini adalah berdasarkan penilaian terhadap faktor yang menyumbang kepada kejadian bencana. Ini melibatkan pengendalian, tafsiran dan perwakilan grafik sejumlah besar data. Keupayaan teknologi Sistem Maklumat Geografi (GIS) yang telah lama bertapak dalam bidang bencana telah membenarkan penyepaduan maklumat pelbagai dimensi melalui model bersesuaian untuk mengezonkan kawasan kerentanan bencana. Rata-rata di Malaysia, teknologi GIS telah diteroka oleh beberapa penyelidik secara meluas dalam bidang bencana seperti dalam Lee dan Jasmi (2005), Mokhtar et al. (2011), Norbazlan dan Pradhan (2014), Nuriah et al. (2017), Pradhan (2010), Samy Ismail dan Mohamed (2013) dan Shahabi et al. (2013).

Dalam konteks kajian ini, tanah runtuh dan banjir cuba diungkap sebagai satu sistem yang berkait rapat secara fizikal oleh geologi, geomorfologi dan juga hidrologi. Kajian ini berusaha melihat bagaimana manipulasi terhadap faktor fizikal ini akibat daripada ledakan populasi dan kepesatan pembangunan akan menyumbang kepada bencana. Attribut terain meliputi topografi, struktur geologi dan geomorfologi telah dipertimbangkan sebagai maklumat pelbagai dimensi penilaian kerentanan tanah runtuh dan banjir. Justeru, berbekalkan keupayaan GIS sebagai platform, objektif kajian ini adalah untuk mengenal pasti maklumat pelbagai dimensi yang menyumbang kepada bencana di UKM dan membangunkan sebuah peta kerentanan tanah runtuh dan banjir untuk menyokong dalam membuat keputusan secara termaklum.

\section{KAWASAN KAJIAN}

UKM Bangi seperti dalam Rajah 1 terletak di pertemuan antara Sungai Langat dan Sungai Semenyih dengan majoriti populasinya merupakan pelajar. Kelas guna tanah semasa yang dikenal pasti dalam UKM meliputi tepu bina, hutan, pertanian dan juga badan air. Huraian untuk setiap kelas guna tanah adalah seperti dalam Jadual 1. Kelas tepu bina mempunyai keluasan saiz yang terbesar antara kelas-kelas yang lain.

Asas pemilihan kampus ini sebagai lokasi kajian adalah berdasarkan tiga faktor: kepesatan aktiviti tepu bina yang berlaku di sekitar kampus; UKM telah mengalami banyak insiden kegagalan cerun dan tanah runtuh serta beberapa kali insiden kenaikan air sejak kampus ini mula beroperasi. Insiden yang berlaku sebelum ini telah direkod dalam satu inventori dan boleh dirujuk dalam Nurfashareena et al. (2016). Kebanyakan kejadian telah berlaku berdekatan dengan kediaman pelajar, bangunan akademik dan juga aset penting UKM seperti Bangunan Elektron Mikroskopi yang menyebabkan gangguan terhadap waktu pembelajaran; UKM bertindak sebagai sebuah pihak berkepentingan kecil yang bertanggungjawab atas segala penyelenggaraan seluruh kawasan kampus ini. 


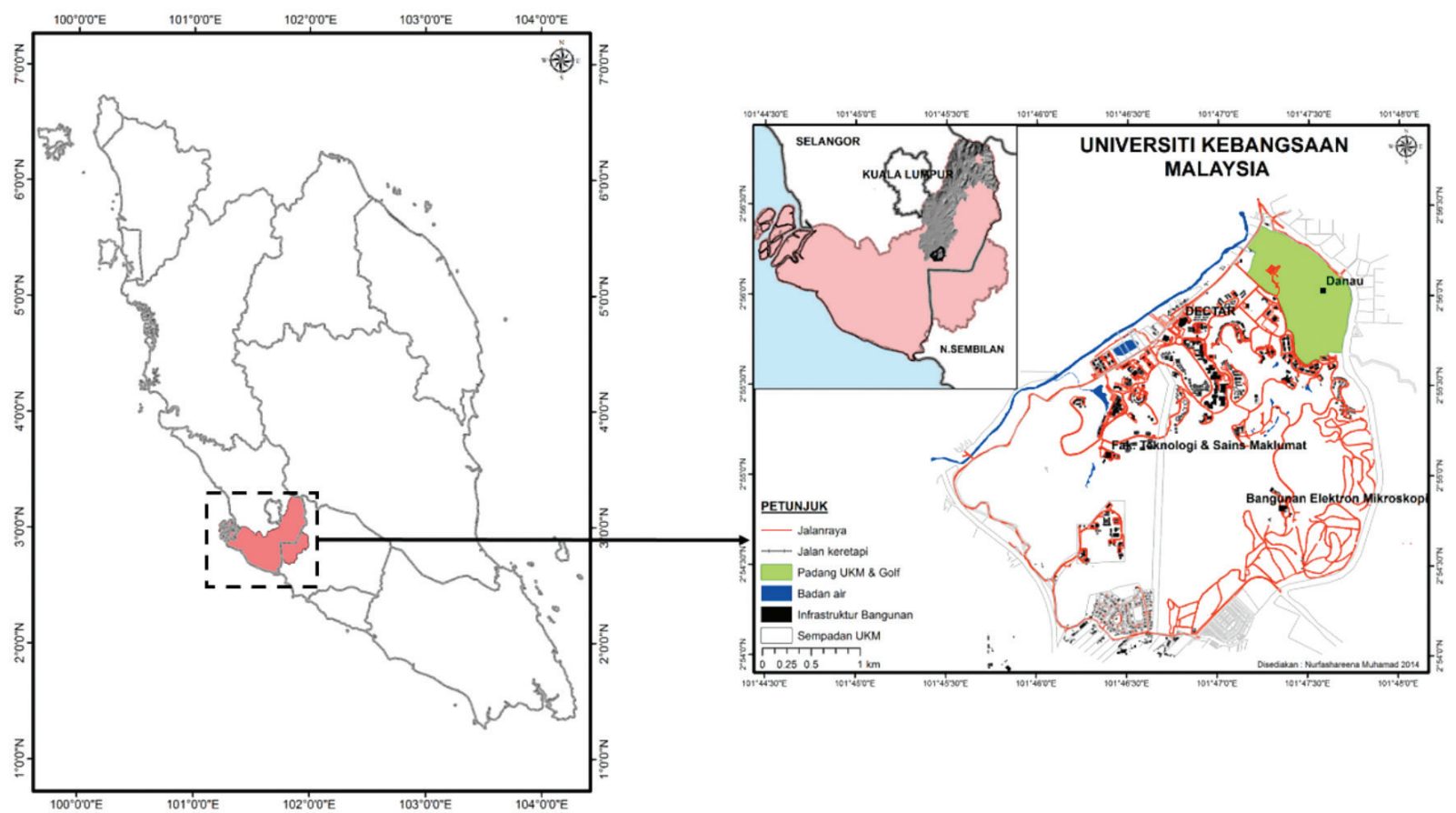

RAJAH 1. Lokasi Universiti Kebangsaan Malaysia di dalam Lembangan Langat

JADUAL 1. Kelas guna tanah UKM bersama huraian kelas

\begin{tabular}{ll}
\hline Kelas guna tanah & Huraian \\
\hline Tepu bina & $\begin{array}{l}\text { Tanah kediaman, kawasan fakulti, kawasan kolej kediaman, infrastruktur asset } \\
\text { universiti, tanah rekreasi dan semua bentuk pembangunan berstruktur }\end{array}$ \\
Hutan & Semua jenis tumbuhan hutan dan hutan simpan UKM \\
Pertanian & Tanaman herba dan kelapa sawit \\
Badan air & Sungai, tasik dan semua bentuk badan air \\
Tanah kosong & Tanah lapang dan semua bentuk tanah terbuka \\
\hline
\end{tabular}

\section{METOD}

Pendekatan heuristik melalui penilaian pakar dalam mengelaskan bahaya telah digunakan dalam kajian ini (Ayalew et al. 2005; Castellanos Abella 2008; Soeters \& van Westen 1996; van Westen 1994). Teknik pemetaan tidak langsung digunakan dengan menggabungkan peta kualitatif yang diberi nilai pemberat berdasarkan daripada penilaian pakar (Hervas \& Bobrowsky 2009; Soeters \& van Westen 1996; van Westen 2004). Melalui pendekatan ini, tiga kaedah utama telah digunakan untuk menghasilkan peta kerentanan tanah runtuh dan banjir meliputi analisis kandungan untuk mengenal pasti kriteria yang menyumbang kepada tanah runtuh dan banjir, elisitasi pakar untuk memberi nilai pemberat terhadap kriteria dan analisis tindan-lapis untuk memproses dan menjana peta tematik.

Analisis kandungan terhadap kepustakaan digunakan untuk mengenal pasti maklumat pelbagai dimensi yang dikelaskan kepada kriteria penyebab dan kriteria pencetus untuk kedua-dua bahaya. Untuk memastikan kebolehpercayaan dan kerelevanan pemilihan kriteria, kajian ini merujuk Ayalew et al. (2005) yang mana kriteria terpilih seharusnya bersifat operasi, lengkap, tidak seragam, boleh diukur dan tidak berulang. Kesemua kriteria ditukarkan ke format GIS integer raster cell 30 $\times 30 \mathrm{~m}$ membentuk lapisan kualitatif sebelum analisis tindan-lapis dapat dilakukan.

Elisitasi pakar melalui perbincangan kumpulan fokus atau Focus Group Discussion (FGD) telah digunakan untuk mendapatkan nilai pemberat dan pemeringkatan terhadap kriteria penyebab dan pencetus (Rajah 2). Enam orang pakar yang berkelayakan dengan pengalaman lapangan yang melebihi 15 tahun serta mempunyai latar belakang hampir sama daripada organisasi yang berbeza telah dikumpulkan dalam satu pertemuan FGD untuk menjalankan proses elisitasi (Ayyub 2001; Chi et al. 1988). Penilaian pemeringkatan diberikan mengikut peratusan pengaruh terhadap semua peta kriteria yang mempengaruhi kejadian tanah runtuh dan banjir. Semua nilai tersebut akan dihitung melalui analisis tindan lapis. 


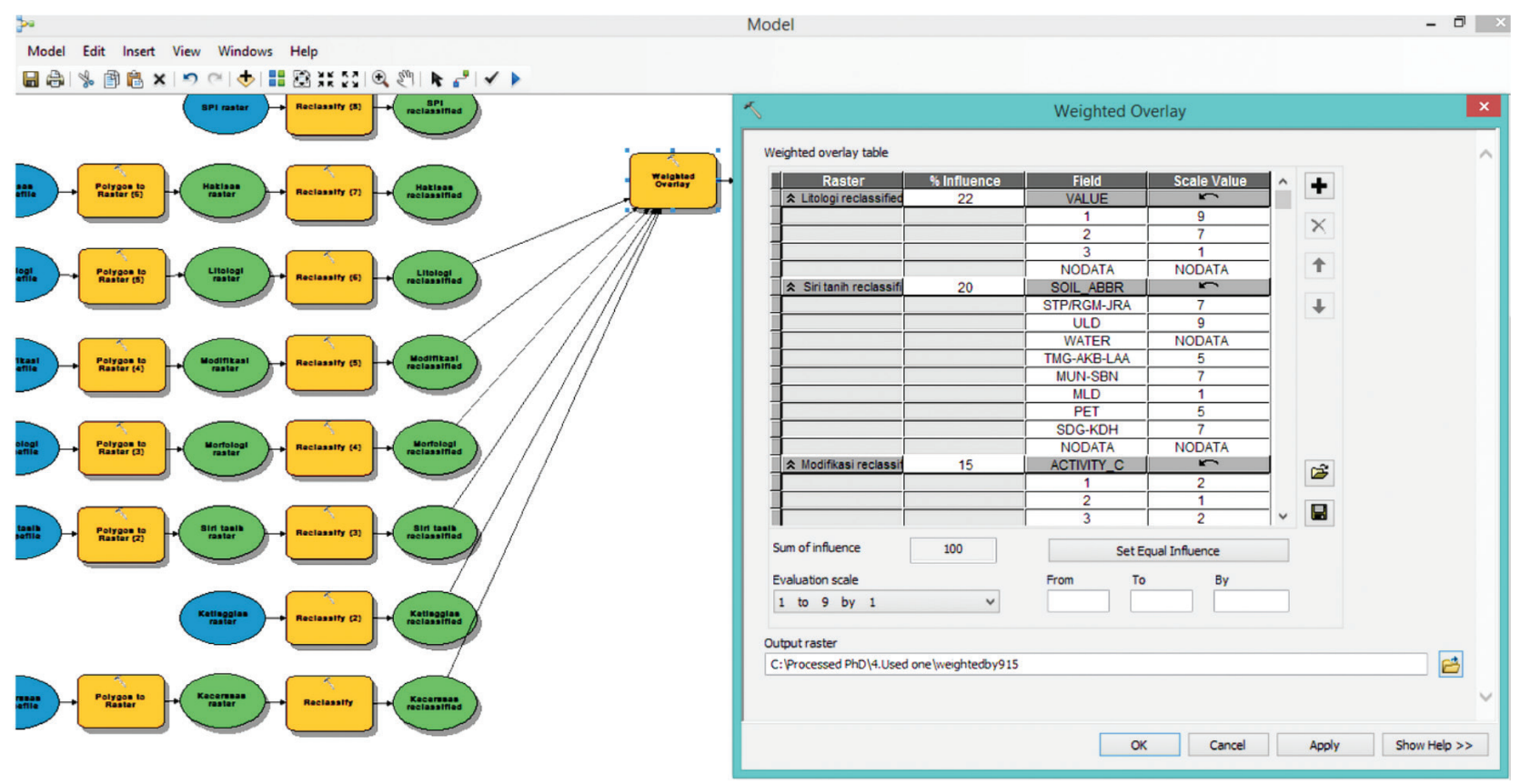

RAJAH 2. Antara muka Weighted Overlay di dalam Model Builder ARCGIS dengan nilai pemeringkatan dan pemberat daripada pakar

Teknologi GIS telah dioptimumkan pada tahap ini dengan operasi analisis tindan lapis seperti perhitungan Weighted Overlay, dilihat sebagai tulang belakang dalam memasukkan dan menganalisis nilai pemberat dan pemeringkatan yang diperoleh. Analisis ini amnya digunakan secara meluas seperti dalam Farhan dan Akhyar (2017) menganalisis peta Tsunami di Acheh; Sinha et al. (2016) memeta bahaya dan keterancaman gempa bumi di India; Basharat et al. (2016) dan Shit et al. (2016) masing-masing dalam pemetaan kerentanan tanah runtuh di Pakistan dan India; Isa et al. (2015) untuk menganalisis kesesuaian tapak penempatan semula banjir di Nigeria; Ahmed (2015) memeta kerentanan tanah runtuh di Bangladesh dan Feizizadeh et al. (2014) menilai multikriteria tanah runtuh. Di Malaysia, analisis ini digunakan dalam pemetaan zon tanah runtuh di Cameron Highlands oleh Abd. Nasir et al. (2012) dan pemetaan bahaya banjir di kawasan Lembangan Kayu Ara oleh Sina Alaghmand et al. (2010).

Hasil analisis telah membentuk peta kerentanan tanah runtuh dan banjir yang terdiri daripada tahap kerentanan sangat tinggi kepada sangat rendah. Pengelasan kelas kerentanan seperti dalam Jadual 2 dibentuk mengikut taburan data daripada histogram yang terhasil daripada peta tersebut. Kajian ini memilih kuantil untuk mengelas semula julat kerana teknik ini berupaya mempamerkan variasi yang baik terhadap nilai-nilai kecil yang kritikal dengan terperinci; dan kebarangkalian untuk wujudnya kelas yang kosong, kelas yang mempunyai data terlalu sedikit mahupun terlalu banyak adalah tiada (Campbell \& Shin 2015; ESRI 2015, 2013).

\section{KEPUTUSAN DAN PERBINCANGAN}

Setiap kriteria yang dipilih memiliki pelbagai sub-kelas yang memberi pengaruh yang berbeza terhadap tanah runtuh dan banjir (Rajah 3). Pantauan yang dilakukan terhadap setiap sub-kelas dengan kekerapan tanah runtuh dan banjir mendapati, tanah runtuh dan banjir lebih kerap berlaku pada sub-kelas yang banyak terlibat dengan aktiviti manusia seperti pembangunan. Malaysia merupakan negara yang beriklim tropika yang mempunyai taburan hujan yang tinggi. Menurut Mokhtar et al. (2011), taburan dan keamatan hujan yang tinggi menjadi agen pencetus kepada kejadian tanah runtuh di Malaysia. Bujang et al. (2008) dan Nurfashareena et al. (2013) berpendapat bahawa jumlah hujan beserta suhu tahunan yang tinggi menggiatkan lagi proses luluhawa sehingga mampu menerobos $100 \mathrm{~m}$ ke dalam tanah dan seterusnya mampu menghasilkan kejadian runtuh berskala besar yang yang kebiasaannya dicatatkan berlaku dari September hingga Januari berdasarkan laporan hujan yang sangat tinggi dalam tempoh ini.

Sama seperti tanah runtuh, banjir di Malaysia juga sering berlaku pada musim hujan yang tinggi dan memberi kesan kepada sungai utama (Tan \& Pereira 2013). Hal ini turut dijelaskan oleh Lee dan Pradhan (2007) dengan banjir di Malaysia dicetuskan daripada insiden monsun ataupun hujan perolakan yang mengakibatkan sumber air larian yang banyak. Kejadian ini diburukkan lagi dengan kehadiran pembangunan yang pesat menyebabkan banyak permukaan tidak telap air yang lazim berlaku pada kawasan tadahan sungai diiringi dengan kemerosotan kapasiti pegangan air sungai. Kajian ini mendapati hujan 
JADUAL 2. Penjelasan untuk setiap tahan kerentanan

\begin{tabular}{|c|c|c|}
\hline Tahap kerentanan & Kriteria & Penjelasan \\
\hline Sangat tinggi & $\begin{array}{l}\text { Kehadiran hampir semua kriteria penyebab } \\
\text { dengan nilai pemberat dan pemeringkatan yang } \\
\text { tinggi }\end{array}$ & $\begin{array}{l}\text { Pembangunan tidak boleh dijalankan kecuali } \\
\text { adanya kajian terperinci ke atas kawasan ini. } \\
\text { Dikatakan sebagai kawasan paling lemah. }\end{array}$ \\
\hline Tinggi & & $\begin{array}{l}\text { Langkah berjaga-jaga harus diambil. } \\
\text { Dikatakan sebagai kawasan 'lemah' }\end{array}$ \\
\hline Sederhana & $\begin{array}{l}\text { Beberapa kriteria yang hadir dengan nilai } \\
\text { pemberat dan pemeringkatan yang rendah }\end{array}$ & $\begin{array}{l}\text { Kecenderungan untuk kejadian bencana pada } \\
\text { tahap tidak membimbangkan }\end{array}$ \\
\hline \multicolumn{3}{|l|}{ Rendah } \\
\hline $\begin{array}{l}\text { Sangat rendah atau tiada } \\
\text { maklumat }\end{array}$ & $\begin{array}{l}\text { Semua kriteria tidak hadir. Berdasarkan kriteria } \\
\text { dan kaedah digunakan, bencana mungkin tidak } \\
\text { signifikan }\end{array}$ & $\begin{array}{l}\text { Kawasan paling stabil di mana sepatutnya } \\
\text { tidak akan berlaku bencana }\end{array}$ \\
\hline
\end{tabular}

Sumber: Ubah suai daripada Meneround \& Calvino 1976; Resource Inventory Committee 1996; Norbert et al. 2009
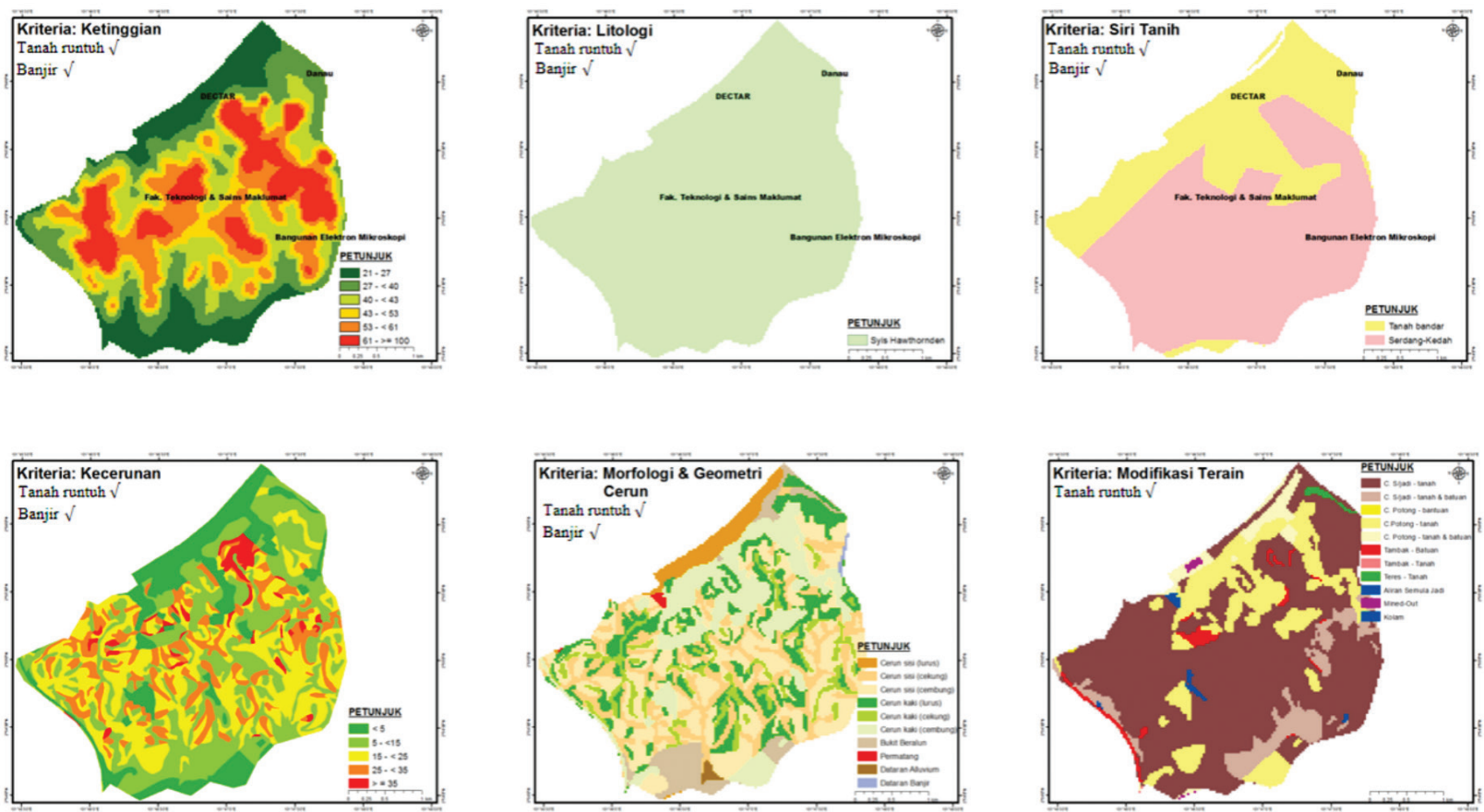

RAJAH 3. Kriteria penyebab untuk tanah runtuh dan banjir

merupakan faktor yang dikenal pasti sebagai pencetus kepada tanah runtuh dan juga banjir.

\section{TANAH RUNTUH}

Penghasilan peta kerentanan tanah runtuh adalah berdasarkan analisis terhadap kriteria seperti litologi, siri tanih, morfologi dan geometri cerun, purata hujan, modifikasi terain, ketinggian dan kecerunan. Litologi dianggap sebagai pemboleh ubah bebas kerana strukturnya yang berbeza cenderung membawa kepada perubahan dalam kestabilan dan kekuatan batu bersama tekstur tanah yang berbeza-beza (Anbalagan 1992; Saha et al. 2002; Shahabi et al. 2013). Kajian ini mendapati, kriteria litologi sering digunakan di dalam analisis kerentanan untuk Negara-negara beriklim Tropika seperti dalam Arnous (2011), Nuriah et al. (2013), Pradhan \& Lee (2010), Saha et al. (2002), Sarkar et al. (2006) dan Temesgen et al. (2001). Untuk siri tanih, sifat tanih yang berbeza pada keadaan cerun yang berbeza akan memberi pengaruh besar terhadap tanah runtuh pada tahap-tahap tertentu (Gorsevski et al. 2006; Mokhtar 2011). Wan Mohd Muhiyuddin dan Ruslan 
(2004) dalam kajian beliau di aliran atas Lembangan Langat atau dikenali sebagai Sub-Lembangan Langat turut menggunakan kriteria ini dalam pemodelan tanah runtuh diikuti oleh Ainon Nisa et al. (2012), Mezughi et al. (2012), Nuriah et al. (2017) dan Shahabi dan Mazlan (2015) masing-masing menggunakan kriteria ini dalam kajian di Kuala Lumpur, Kelantan, Tanah Tinggi Cameron dan Pulau Pinang.

Morfologi dan geometri cerun menggambarkan rupa bentuk fizikal cerun dan bentuk umum profil cerun tersebut (Dai \& Lee 2002). Keadaan cerun yang tinggi dan bersudut besar akan meningkatkan tegasan ricih bahan cerun (Zulfahmi et al. 2007). Penggunaan kriteria ini ditemui dalam kajian tanah runtuh oleh Abd. Manap et al. (2010), Mezughi et al. (2012) dan Pradhan dan Lee (2010). Kriteria ini turut dipertimbangkan oleh Jabatan Mineral dan Geosains Malaysia (2006) dalam penilaian terain geologi. Ketinggian merupakan antara kriteria paling penting yang mempengaruhi ketidakstabilan cerun dan ia mempengaruhi permukaan muka bumi dan ciri-ciri topografi yang lain seperti profil kelengkungan, kecerunan cerun dan juga aspek kecerunan (Saadatkhah et al. 2014). Kriteria ini diwakilkan dalam grid sebagai DEM yang dijana melalui satu modul untuk menghasilkan DEM daripada garis kontur dalam GIS. Kriteria ini menjadi kelaziman dalam kajian berkaitan tanah runtuh boleh didapati dalam kajian seperti Arnous (2011), Ilanloo (2011), Norbert et al. (2009), Pradhan dan Lee (2010), dan Shahabi dan Mazlan (2015).

Modifikasi terain melibatkan aspek geoteknikal dan ketidakstabilan cerun berdasarkan sifat semula jadi cerun atau cerun buatan manusia merangkumi cerun potong dan tambakan. Semasa FGD dijalankan, beberapa pakar berpendapat ketidakstabilan cerun kerap kali berlaku pada cerun buatan manusia. Kecerunan merupakan salah satu cirian geomorfologi yang memberi pengaruh besar terhadap kerentanan tanah runtuh (Ayalew et al. 2005; Dai et al. 2002). Kriteria ini antaranya boleh didapati di dalam kajian oleh Bhatt et al . (2013), Ilanloo (2011), Lim (2004), Nithya dan Prasanna (2010) dan Nuriah et al. (2017).

Peta kerentanan tanah runtuh dilihat secara keseluruhannya diliputi oleh empat jenis kerentanan iaitu daripada rendah hingga ke sangat tinggi. Terain telah dikelaskan kepada beberapa tahap kerentanan yang boleh dirujuk dalam Jadual 3. Kelas kerentanan tinggi merupakan kelas terbesar di UKM dengan keluasan sebanyak 6.10 $\mathrm{km}^{2}$ atau $51.91 \%$ iaitu hampir separuh daripada jumlah keluasan asal kampus tersebut. Kelas kerentanan ini disahkan dengan lokasi insiden lepas yang telah direkod dalam Nurfashareena (2016). Analisis mendapati kesemua taburan tanah runtuh berlaku pada kelas kerentanan sederhana, tinggi dan sangat tinggi. Hampir separuh daripada jumlah taburan tanah runtuh berlaku pada kelas kerentanan tinggi iaitu $57.14 \%$ yang merupakan peratusan terbesar daripada jumlah keseluruhan. Untuk mempertimbangkan kesesuaian pembinaan dalam UKM, lapisan binaan struktur semasa telah ditindan-lapis secara mudah dengan peta kerentanan tanah runtuh.

Tindan-lapis tersebut mendapati sebahagian besar daripada binaan struktur termasuk fakulti, pejabat, kolej kediaman, binaan aset penting universiti dan beberapa lagi terletak pada kawasan berkerentanan tinggi dan sangat tinggi (Rajah 4). Perbandingan terhadap peta kerentanan dengan lokasi hotspot dan zon prioriti UKM daripada Nurfashareena et al. (2013) turut ditentusahkan. Berdasarkan Rajah 4, lima lokasi hotspot dan kawasan prioriti Kolej Ungku Omar dan FSSK berada pada kelas kerentanan tinggi dan sangat tinggi. Merujuk kepada kajian Ibrahim (1987), kawasan UKM yang didominasi oleh kelas kerentanan tinggi dan sangat tinggi dijelaskan sebagai kawasan yang cenderung untuk berlakunya tanah runtuh atau dikenali sebagai kawasan rentan. Ini kerana terdapat beberapa faktor yang mempengaruhi kawasan tersebut seperti keadaan cerun uzur; dalam kebanyakan kes, cerun di sekitar UKM telah dipotong sejak 20-30 tahun dahulu pada akhir tahun 1970-an dan awal 1980-an; keluluhawaan dan hakisan telah melemahkan ketahanan bahan dalam cerun di samping kestabilan cerun yang kian merosot (Nurfashareena et al. 2013).

Malah kebanyakan cerun yang gagal merupakan kes perulangan sama ada pada cerun tersebut atau bersebelahan mempunyai petanda sejarah gerakan cerun pada masa lepas; tanda-tanda ini dapat diperhatikan daripada kerja lapangan melalui kesan ceburam cerun tersebut sama ada pernah bergerak atau gagal dengan sokongan rekod penyelenggaraan (Nurfashareena et al. 2013). Selain itu, perubahan bentuk rupa bumi akibat pembangunan pesat yang dihadapi terutama sekali yang dijalankan di atas cerun tidak bersesuaian turut meningkatkan tahap kerentanan kawasan tersebut. Pada masa yang sama, kajian turut mendapati kelas kerentanan sederhana majoritinya berada di kawasan hutan yang belum diteroka atau hutan simpan yang berada pada kecuraman dan bertopografi tinggi.

JADUAL 3. Jumlah serta peratusan keluasan dan bilangan tanah runtuh untuk setiap kelas kerentanan

\begin{tabular}{lccc}
\hline Kelas kerentanan tanah runtuh & $\begin{array}{c}\text { Keluasan } \\
\left(\mathrm{km}^{2}\right)\end{array}$ & $\begin{array}{c}\text { Peratusan keluasan } \\
(\%)\end{array}$ & $\begin{array}{c}\text { Peratusan bilangan tanah } \\
\text { runtuh }(\%)\end{array}$ \\
\hline Sangat rendah & - & - & - \\
Rendah & 0.21 & 1.79 & - \\
Sederhana & 4.45 & 37.87 & 28.57 \\
Tinggi & 6.10 & 51.91 & 57.14 \\
Sangat tinggi & 0.99 & 8.43 & 14.29 \\
Tiada data & - & - & - \\
\hline
\end{tabular}




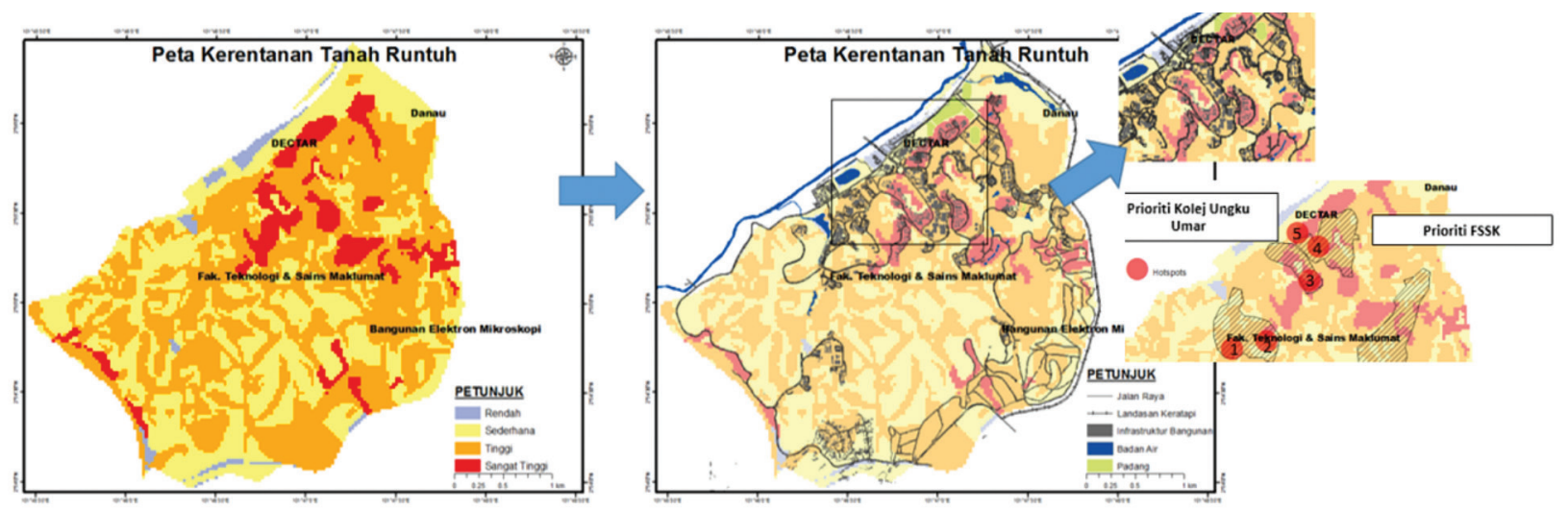

RAJAH 4. Peta kerentanan tanah runtuh dan peta bersama lapisan binaan struktur serta lokasi hotspot

Sekiranya terdapat keperluan untuk menjalankan aktiviti tepu bina di kawasan tersebut, langkah berjaga-jaga harus diambil kerana dikhuatiri modifikasi ke atas kawasan tersebut akan meningkatkan lagi tahap kerentanan.

\section{BANJIR}

Untuk peta kerentanan banjir, analisis adalah berdasarkan kriteria seperti ketinggian, morfologi dan geometri cerun, siri tanih, litologi dan kecerunan. Ketinggian dipertimbangkan kerana banjir sering dikaitkan dengan kawasan yang rendah atau mempunyai topografi yang rata. Kajian seperti dari Ramlal dan Baban (2008) dan Ituen et al. (2014) turut menggunakan ketinggian sebagai parameter untuk menilai banjir. Penggunaan kriteria morfologi dan geometri cerun untuk banjir adalah terhad. Namun kriteria ini dipilih disebabkan kewujudan beberapa sub-kelas penting berkaitan banjir seperti dataran aluvium, dataran banjir dan lembah saliran. Siri tanih pula dipilih kerana setiap tanih mempunyai sifat fizikal yang berlainan yang mempunyai keupayaan yang berlainan dalam memberi pengaruh kepada kejadian banjir. Kajian oleh Tehrany et al. (2015) dalam membangunkan peta kerentanan banjir untuk kawasan Terengganu turut menggunakan siri tanih sebagai salah satu parameter penilaian.

Pemilihan litologi pula berdasarkan sifat batuan dasar yang wujud pada dataran banjir mempunyai sifat tertentu yang memberi kesan terhadap berlakunya bencana ini (Jansen 2006). Walaupun kecerunan seringkali dikaitkan dengan tanah runtuh, namun ia juga mempunyai pengaruh kepada banjir. Kecerunan yang tinggi lazimnya berada lebih dekat dengan sumber saliran dan terendah pada permukaan dataran yang berupaya menjejaskan tahap kerentanan sesuatu kawasan melalui tempoh masa dan halaju yang diambil oleh air larian di samping memberi kesan terhadap jumlah penyusupan (Ehsan \& Marx 2011; Goldworthy \& Jackson 2000; Nelson \& Dube 2015). Pradhan (2009) dan Tehrany et al. (2015) masing-masing telah mengambil kira kriteria ini dalam analisis kerentanan banjir di Kelantan dan Terengganu.

Peta tematik banjir yang diperoleh seperti dalam Rajah 5 memberi gambaran bahawa selain tanah runtuh, UKM juga terdedah kepada bahaya banjir. Perbezaan corak taburan tahap kerentanan dilihat sangat ketara antara bahagian atas dan bawah kampus ini. Keadaan ketinggian yang berada pada $<100 \mathrm{~m}$ memungkinkan kawasan kampus cenderung untuk mengalami banjir. Kampus ini secara keseluruhannya dilihat berada pada empat tahap kerentanan iaitu daripada rendah hingga ke sangat tinggi. Keluasan untuk kesemua kelas telah dihitung dan dijadualkan seperti dalam Jadual 4. Kajian mendapati kelas kerentanan sederhana merupakan kelas terbesar untuk UKM dengan keluasan sebanyak 6.5 $\mathrm{km}^{2}$ bersamaan dengan $55.6 \%$ daripada keluasan asal.

Lapisan binaan struktur semasa telah ditindan-lapis dengan peta kerentanan banjir dan mendapati keseluruhan bahagian atas kawasan UKM merangkumi Danau dan Dewan Canselor berada pada kelas kerentanan sangat tinggi. Pada masa yang sama, letakan binaan struktur di sepanjang laluan utama ke Pusanika dan Perpustakaan Tun Sri Lanang yang berhampiran dengan satu saliran sungai kampus berada dalam kelas kerentanan tinggi. Sebahagian besar kawasan kerentanan yang sangat tinggi dan juga tinggi berada pada keadaan morfologi campuran antara bukit beralun dan cerun kaki. Terdapat kemungkinan untuk berlakunya kenaikan air atau banjir kilat pada cerun kaki apabila wujudnya perubahan sudut cerun secara mendadak dengan jumlah takungan air yang banyak menyebabkan limpahan dengan penurunan yang pantas apabila berlakunya hujan lebat. Kewujudan aktiviti tepu bina pada kawasan tersebut akan meningkatkan risiko terhadap banjir. Sungguhpun kelas kerentanan sederhana menjelaskan kecenderungan untuk berlakunya banjir pada tahap tidak membimbangkan, aktiviti tepu bina yang akan dijalankan di kawasan ini harus disertai dengan langkah-langkah mitigasi banjir seperti pembangunan sistem pengurusan air ribut. Ketidaksesuaian pembinaan yang mengabaikan keadaan morfologi muka bumi akan mendedahkan pembangunan tersebut kepada risiko banjir. Walaupun sebelum ini UKM hanya mengalami beberapa insiden kenaikan air yang kecil, kewujudan peta kerentanan banjir merupakan satu keperluan dalam perancangan guna tanah kampus ini. Ia memberi input kepada Prasarana UKM untuk mengambil langkah mitigasi banjir pada kawasan tertentu sebelum pembangunan dijalankan. Peta ini turut 
JADUAL 4. Jumlah serta peratusan keluasan dan bilangan banjir untuk setiap kelas kerentanan

\begin{tabular}{lccc}
\hline Kelas kerentanan banjir & $\begin{array}{c}\text { Keluasan } \\
\left(\mathrm{km}^{2}\right)\end{array}$ & $\begin{array}{c}\text { Peratusan keluasan } \\
(\%)\end{array}$ & $\begin{array}{c}\text { Peratusan bilangan banjir } \\
(\%)\end{array}$ \\
\hline Sangat rendah & - & - & - \\
Rendah & 0.2 & 1.7 & - \\
Sederhana & 6.5 & 55.6 & - \\
Tinggi & 3.4 & 29.1 & - \\
Sangat tinggi & 1.6 & 13.7 & - \\
Tiada data & 0.0 & 0.0 & - \\
\hline
\end{tabular}
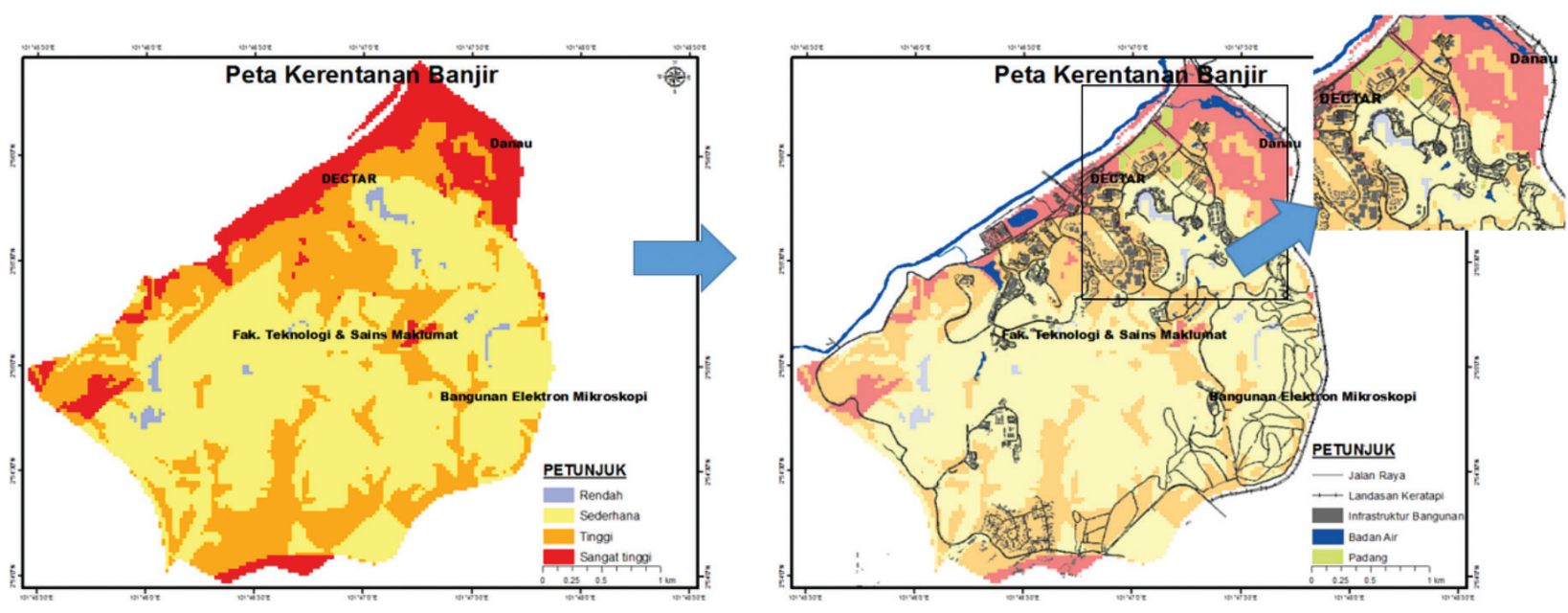

RAJAH 5. Peta kerentanan banjir dan peta bersama lapisan binaan struktur

memberi gambaran umum bahawa, jika pembangunan guna tanah UKM tidak ditadbir urus dengan betul, kampus ini juga cenderung mengalami banjir mungkin bukan pada masa sekarang, tetapi di masa hadapan.

Walaupun sebelum ini UKM hanya mengalami beberapa insiden kenaikan air yang kecil, kewujudan peta kerentanan banjir merupakan satu keperluan dalam perancangan guna tanah kampus ini. Ia memberi input kepada Prasarana UKM untuk mengambil langkah mitigasi banjir pada kawasan tertentu sebelum pembangunan dijalankan. Peta ini turut memberi gambaran umum bahawa, jika pembangunan guna tanah UKM tidak ditadbir urus dengan betul, kampus ini juga cenderung mengalami banjir mungkin bukan pada masa sekarang, tetapi pada masa hadapan.

\section{KESIMPULAN}

UKM merupakan sebuah institusi yang memainkan peranan penting dalam menghasilkan modal insan yang cemerlang. Beberapa insiden bencana yang sering berlaku berdekatan dengan kediaman pelajar, bangunan akademik dan juga aset UKM telah menyebabkan gangguan terhadap waktu pembelajaran yang dikhuatiri akan memberi kesan terhadap mutu modal insan kelak. Pempraktisan guna tanah yang terancang memainkan peranan penting dalam memastikan pengurusan bencana yang lebih berkesan dan guna tanah dapat ditadbir-urus secara lestari. Justeru, Prasarana UKM memerlukan medium perancangan yang berupaya menyumbang dalam pengurusan guna tanah untuk menyokong dalam membuat keputusan termaklum. Peta kerentanan tanah runtuh dan banjir telah membahagi permukaan terain kepada beberapa unit tahap kerentanan terdiri daripada sangat rendah kepada sangat tinggi. Peta ini dilihat sebagai satu inisiatif dan keperluan dalam memastikan pengurusan guna tanah yang mampan di samping menangani masalah bencana di UKM dengan lebih berkesan. Sebagai satu medium yang bermaklumat, peta menyerlahkan nilai kritikal tentang keperluan strategi mitigasi di setiap lokasi kawasan rentan terhadap tanah runtuh dan banjir sebelum aktiviti pembangunan dijalankan. Berikutan itu, peta ini memberi indikasi khusus dengan membenarkan pemantauan tapak dijalankan di setiap lokasi yang berkaitan untuk tindakan lanjut. Pemetaan kerentanan turut dilihat sebagai satu usaha dokumentasi saintifik yang berupaya membantu dan mengukuhkan kredibiliti Prasarana UKM untuk mengurus-tadbir kampus UKM.

Keupayaan GIS dalam kajian ini bukan sekadar menghasilkan peta, malah, peta tersebut merupakan satu inovasi yang mempunyai pangkalan data geografi bertindak sebagai alat yang digunakan oleh pihak berkepentingan untuk menyokong dalam membuat keputusan guna tanah secara termaklum. Selaras dengan inisiatif yang diketengahkan oleh Sendai Framework for Disaster Risk Reduction (SFDRR) yang menyeru semua negara untuk mempertimbangkan unsur inovasi dengan mengoptimumkan penggunaan sains dan teknologi 
untuk setiap perancangan strategi yang dibuat, GIS boleh disifatkan sebagai platform penghasilan input yang termaklum dalam menyokong pihak berkepentingan. Kajian ini turut mempromosi sebuah kampus yang mampan dengan kesemua warganya berdaya tahan, infrastruktur dikekalkan serta persekitaran dan pembangunan ditadbir urus secara lestari.

\section{PENGHARGAAN}

Penyelidikan ini telah dibiayai oleh peruntukan Dana Pembangunan Penyelidikan kod projek DPP-2015-094, Dana APN XX-2014-008 dan Dana Newton-Ungku Omar Fund XX-2017-002. Setinggi-tinggi perhargaan turut dirakamkan kepada pihak Kementerian Pengajian Tinggi Malaysia melalui MyBrain atas bantuan kewangan yang diberikan kepada pengarang pertama. Jutaan terima kasih kepada pihak Jabatan Mineral dan Geosains Selangor, Jabatan Pertanian Malaysia, Jabatan Meterologi Malaysia dan JPP-UKM (Prasarana UKM) atas penyediaan data penting untuk kajian ini.

\section{RUJUKAN}

Abd. Manap, M., Mohammad Firuz, R., Wan Nor Azmin, S. \& Noraini, S. 2010. Application of remote sensing in the identification of the geological terrain features in Cameron Highlands, Malaysia. Sains Malaysiana 39(1): 1-11.

Abd. Nasir, M., Abdul, B. \& Harahap, I.S.H. 2012. Study of regional monsoonal effects on landslide hazard zonation in Cameron Highlands, Malaysia. Arabian Journal of Geosciences 5(5): 1069-1084.

Ahmed, B. 2015. Landslides susceptibility mapping using multicriteria evaluation techniques in Chittagong Metropolitan Area Bangladesh. Landslide 12(6): 1077-1095.

Ainon Nisa, O., Wan Mohd Naim, W.M. \& Noraini, S. 2012. GIS based multi-criteria decision making for landslide hazard zonation. Procedia - Social and Behavioral Sciences 35: 595-602.

Anbalagan, R. 1992. Land hazard evaluation and zonation mapping in mountainous terrain. Engineering Geology 32: 269-277.

Arnous, O. 2011. Integrated remote sensing and GIS techniques for landslide hazard zonation: A case study Wadi Watier Area, South Sinai, Egypt. Journal of Coastal Conservation 15: 477-497.

Ayalew, L., Yamagishi, H., Marui, H. \& Kanno, T. 2005. Landslides in Sado Island of Japan: Part II. GIS-based susceptibility mapping with comparisons of results from two methods and verifications. Engineering Geology 81: 432-445.

Ayyub, B.M. 2001. A practical guide on conducting expertopinion elicitation of probabilities and consequences for corps facilities. Institute of Water Resources Report 01-R-01.

Basharat, M., Shah, H.R. \& Hameed, N. 2016. Landslide susceptibility mapping using GIS and weighted overlay method: a case study from NW Himalayas, Pakistan. Arabian Journal of Geoscience 9: 292.

Bujang, B.K.H., Faisal Ali, David, H.B., Singh, H. \& Husaini Omar. 2008. Landslide in Malaysia: Occurrences, Assessment, Analyses and Remediation. Serdang: Universiti Putra Malaysia.
Bhatt, P.B., Awasthi, K.D., Heyojoo, B.P., Silwal, T. \& Kafle, G 2013. Using geographic information system and analyical hierarchy process in landslide hazard zonation. Applied Ecology and Environmental Sciences 1(2): 14-22.

Campbell, J. \& Shin, M. 2015. Essentials of Geographic Information Systems, v. 1.0. US: Flat World Education Inc.

Castellanos Abella, E.A. \& van Westen, C.J. 2007. Generation of a landslide risk index map for Cuba using spatial multicriteria evaluation. Landslides 4: 311-325.

Chi, M.T.H., Glaser, R. \& Farr, M.J. 1988. The Nature of Expertise. New Jersey: Erlbaum.

Dai, F.C., Lee, C.F. \& Ngai, Y.Y. 2002. Landslide risk assessment and management: An overview. Engineering Geology 64: 65-87.

Ehsan, S. \& Marx, W. 2011. Impact of river valley shape on flow characteristics, Pakistan. Journal of Engineering and Applied Sciences 8: 9-20.

ESRI. 2013. Understanding GIS. http://www.esri.com/what-isgis. Diakses pada 5 November 2013.

ESRI. 2015. Data Classification Methods. http://pro.arcgis. com/en/pro app/help/mapping/symbols-and-styles/dataclassification-methods.htm.

Farhan, A. \& Akhyar, H. 2017. Analysis of tsunami disaster map by GIS: Aceh Singkil-Indonesia. IOP Conference Series. Earth and Environmental Science 56: 012002.

Feizizadeh, B., Roodposhti, M.S., Jankowski, P. \& Blaschke, T. 2014. A GIS-based extended fuzzy multi-criteria evaluation for landslide susceptibility mapping. Computers \& Geosciences 73: 208-221.

Goldsworthy, M. \& Jackson, J. 2000. Active normal fault evolution in Greece revealed by geomorphology and drainage patterns. Journal of the Goelogical Soeciety 157(5): 967-981.

Gorsevski, P.V., Jankowski, P. \& Gessler, P.E. 2006. An heuristic approach for mapping landslide hazard by integrating fuzzy logic with analytic hierarchy process. Control and Cybernetics 35(1): 121-146.

Hervas, J. \& Bobrowsky, P. 2009. Chapter 19 - Mapping: Inventories, susceptibility, hazard and risk. Dlm. LandslidesDisaster Risk Reduction, disunting oleh Sassa, K. \& Canuti, P. Berlin: Springer-Verlag Berlin Heidelberg.

Ibrahim, K. 1987. Survey of slope failures in Selangor. Sains Malaysiana 16(1): 1-14.

Ibrahim, K. 1984. Geological aspect engineering of the earth in Bangi, Selangor. Ilmu Alam 12\&13: 41-54.

Ilanloo, M. 2011. A comparative study of Fuzzy Logic approach for landslide susceptibility mapping using GIS: An experience of Karaj Dam Basin in Iran. Procedia - Social and Behavioral Sciences 19: 668-676.

Isa, I., Muibi, K.H., Alaga, A.T., Babatimehin, O., Ige-Olumide, O., Mustapha, O.O. \& Hafeez, S.A. 2015. Suitability analysis of resettlement sites for flood disaster victims in Lokoja and Evirons. World Environment 5(3): 101-111.

Ituen, U.J., Johnson, I. \& Nyah, N. 2014. Flood hazard assessment and decisions support using Geographic Information System: A case study of Uyo Capital City, Akwa Ibom State, Nigeria. International Journal of Geography and Geology 3(4): 56-67.

Jabatan Mineral dan Geosains Malaysia (JMG). 2006. Data of Geological Terrain Map. Putrajaya: Jabatan Mineral dan Geosains Malaysia.

Jansen, J.D. 2006. Flood magnitude-frequency and lithologic control on bedrock river incision in post-orogenic terrain. Geomorphology 82 (1-2): 39-57. 
Lee, S. \& Pradhan, B. 2007. Landslide hazard mapping at Selangor, Malaysia using frequency ratio and logistic regression models. Landslides 4: 33-41.

Lee, S. \& Jasmi, A.T. 2005. Probabilistic landslide susceptibility and factor effect analysis. Environmental Geology 47(7): 982-990.

Lim, C.S. 2004. Pemetaan geobencana menggunakan Sistem Maklumat Geografi: Kajian kes di Wilayah Lembah Klang. Tesis Sarjana, Universiti Kebangsaan Malaysia (tidak diterbitkan).

Magliulo, P., Di Lisio, A. \& Russo, F. 2009. Comparison of GIS-based methodologies for the landslide susceptibility assessment. Geoinformatica 13(3): 253-265.

McDonald, A.J.W., O'Connor, E.A. \& David, G. 2004. Rapid landslide susceptibility mapping. Conference on GIS and Remote Sensing Application. hlm. 1-11.

Meneround, J.P. \& Calvino, A. 1976. ZERMOS Map, area exposed to risk linked to movement of soil and subsoil at 1: 25000. Dlm. Landslide Hazard Assessment: Summary Review and New Perspectives, disunting oleh Aleotti, P. \& Chowdhury. Bulletin of Engineering Geology and the Environment 58: 21-44.

Mezughi, T.H., Juhari, M.A., Abdul Ghani Rafek \& Ibrahim, A. 2012. Analytical hierarchy process method for mapping landslide susceptibility to an area along the E-W highway (Gerik-Jeli), Malaysia. Asian Journal of Earth Sciences 5(1): 13-24.

Mokhtar, J. \& Mohd Afif, S. 2013. Potensi tanah runtuh bagi cerun-cerun berhampiran kolej kediaman pelajar di Universiti Kebangsaan Malaysia (UKM). Geografia Malaysian Journal of Society and Space 9(3): 107-115.

Mokhtar, J., Abdul Halim, Y. \& Asiah, Y. 2011. Analisis tahap kebolehruntuhan tanah dengan menggunakan skala ROM: Kajian di Kampus Universiti Kebangsaan Malaysia, Bangi. Geografia Malaysian Journal of Society and Space 7(3): 45-55.

Nelson, A. \& Dubem, K. 2015. Channel response to an extreme flood and sediment pulse in a mixed bedrock and gravelbed river. Earth Surface Processes and Landforms 41(2): 178-195.

Nithya, S.E. \& Prasanna, P.R. 2010. An integrated approach with GIS and remote sensing technique for landslide hazard zonation. International Journal of Geomatics and Geosciences 1(1): 66-75.

Norbazlan, M.Y. \& Pradhan, B. 2014. Landslide susceptibility mapping along PLUS expressways in Malaysia using probabilistic based model in GIS. IOP Conference Series: Earth and Environmental Science 20(1): 1-22.

Norbert, S., Juhari, M.A., Azlikamil, N. \& Tan, H.K. 2009. Pemetaan potensi bencana tanah runtuh menggunakan faktor penilaian bencana tanah runtuh dengan pendekatan GIS. Bulletin of the Geological Society of Malaysia 55: 47-53.

Nurfashareena, M. 2016. Bencana semulajadi di kawasan tepu bina: Kajian kes sub-lembangan Langat, Malaysia. Tesis Doktor Falsafah, Universiti Kebangsaan Malaysia (tidak diterbitkan)

Nurfashareena, M., Lim, C.S., Reza, M.I.H. \& Pereira, J.J. 2013. Input geologi untuk sistem sokongan membuat keputusan dalam pengurusan risiko bencana: Kajian kes Universiti Kebangsaan Malaysia. Bulletin of the Geological Society of Malaysia 59: 73-84.
Nuriah, A.M. \& Wan Mohd Muhiyuddin. 2013. Pemetaan zon kebolehrentanan kegagalan cerun di Pulau Pinang menggunakan Rangkaian Saraf Buatan (ANN). Geografia Malaysian Journal of Society and Space 9(1): 34-47.

Nuriah, A.M., Ruslan, R. \& Wan Mohd Muhiyuddin. 2017. Pemodelan ruangan pelbagai jenis kegagalan cerun di Pulau Pinang menggunakan kaedah nisbah kekerapan. Geografi 5(2): 13-26.

Pradhan, B. 2010. Remote sensing and GIS-based landslide hazard analysis and cross-validation using multivariate logistic regression model on three test areas in Malaysia. Advances in Space Research 45(10): 1244-1256.

Pradhan, B.S. \& Lee, S. 2010. Landslide susceptibility assessment and factor effect analysis: Backpropagation artificial neural networks and their comparison with frequency ratio and bivariate logistic regression modelling. Environmental Modelling \& Software 25: 747-759.

Ramlal, B. \& Baban, S.M.J. 2008. Developing a GIS based integrated approach to flood management in Trinidad, West Indies. Journal of Environmental Management 88: 11311140.

Resources Inventory Committee. 1996. Guidelines and Standards for Terrain Mapping in British Columbia. Government of British Columbia. Victoria, B.C.

Saadatkhah, N., Azman, K. \& Lee, M.L. 2014. Qualitative and quantitative landslide susceptibility assessments in Hulu Kelang area, Malaysia. Electronic Journal of Geotechnical Engineering 19: 545-563.

Saha, A.K., Gupta, R.P. \& Arora, M.K. 2002. GIS-based landslide hazard zonation in the Bhagirathi (Ganga) Valley, Himalaya. International Journal of Remote Sensing 23(2): 357-369.

Samy Ismail, E. \& Mohamed, M.M. 2013. Natural hazards susceptibility mapping in Kuala Lumpur, Malaysia: An assessment using remote sensing and geographic information system (GIS). Geomatics, Natural Hazards and Risk 4(1): 71-91.

Santangelo, N., Santo, A., Di Crescenzo, G., Foscari, G., Liuzza, V., Sciarrotta, S. \& Scorpio, V. 2011. Flood susceptibility assessment in a highly urbanized alluvial fan: The case study of Sala Consilina (Southern Italy). Natural Hazards and Earth System Science 11(10): 2765-2780.

Sarkar, S., Kanungo, D.P., Patra, A.K. \& Kumar, P. 2006. GIS based landslide susceptibility mapping: A case study in Indian Himalaya. Dlm. Disaster Mitigation of Debris Flows, Slope Failures and Landslides. Tokyo: Universal Academy Press Inc. hlm. 617-624.

Shahabi, H. \& Mazlan, H. 2015. Landslide susceptiblility mapping using GIS-based statistical models and remote sensing data in tropical environment. Scientific Reports 5: Article number 9899.

Shahabi, H., Ahmad, B.B. \& Khezri, S. 2013. Evaluation and comparison of bivariate and multivariate statistical methods for landslide susceptibility mapping (Case Study: Zab Basin). Arab Journal of Geoscience 6: 3885-3907.

Shit, P.K., Bhunia, G.S. \& Maiti, R. 2016. Potential landslide susceptibility mapping using weighted overlay model (wom). Modeling Earth Systems and Environment 2: 21.

Sina Alaghman, R.A., Ismail, A.\& Vosoogh, B. 2010. GIS-based river flood hazard mapping in urban area: A case study in Kayu Ara River Basin, Malaysia. International Journal of Engineering and Technology 2(6): 488-500. 
Sinha, N., Priyanka, N. \& Joshi, P.K. 2016. Using spatial multicriteria analysis and rangking tool (SMART) in earthquake risk assessment: A case study of Delhi region, India. Geomatics, Natural Hazards and Risk 7(2): 680-701.

Soeters, R.\& Van Westen, C.J. 1996. Slope instability recognition, analysis, and zonation. Dlm. Landslides, Investigation and Mitigation, disunting oleh Turner, A.K. \& Schuster, L.R. Washington: National Academy Press. hlm. 129-177.

Tan, C.T. \& Pereira, J.J. 2013. Management of climate change and disaster risk. The Malaysia perspective. Dlm. Climate Change and Disaster Risk Management, disunting oleh Filho, W.L. Berlin: Springer-Verlag Berlin Heidelberg. hlm. 193-204.

Tehrany, M.S., Pradhan, B. \& Jebur, M.N. 2015. Flood susceptibility analysis and its verification using a novel ensemble support vector mechine and frequency ratio method. Stochastic Environmental Research and Risk Assessment 29(4): 1149-1165.

Temesgen, B., Mohammed, M.U. \& Korme, T. 2001. Natural hazard assessment using GIS and remote sensing methods, with particular reference to the landslides in the Wondegenet Area, Ethiopia. Physic and Chemistry of the Earth, Part C: Solar, Terrestrial \& Plenary Science 26(9): 665-675.

Van Westen, C.J. 1994. GIS in landslide hazard zonation: A review, with examples from the Andes of Colombia. Dlm Mountain Environments and Geographic Information System, disunting oleh Price, M. \& Heywood, I. London: Taylor \& Francis.
Wan Mohd Muhiyuddin, W.I. \& Ruslan, R. 2004. Modelling landslide using GIS and RS: A case study of upper stream of Langat River Basin, Malaysia. Malaysian Journal of Environmental Management 5: 113-122.

Zulfahmi, A.R., Sahibin, A.R., Jasni, Y. \& Wan Muhd Razi, I. 2007. Tinjauan awal potensi ketidakstabilan cerun dan cirian fiziko-kimia tanah di Cameron Highlands, Pahang. Sains Malaysiana 36(2): 105-116.

Pusat Kajian Bencana Asia Tenggara (SEADPRI-UKM)

Institut Alam Sekitar dan Pembangunan

Universiti Kebangsaan Malaysia

43600 UKM Bangi, Selangor Darul Ehsan

Malaysia

Pengarang untuk surat-menyurat; email: joy@ukm.edu.my

Diserahkan: 14 Februari 2018

Diterima: 1 September 2018 